\title{
Inclusive public participation in health: Policy, practice and theoretical contributions to promote the involvement of marginalised groups in healthcare
}

\author{
Cláudia de Freitas ${ }^{\mathrm{a}, \mathrm{c}, \mathrm{d}, *}$, Graham Martin ${ }^{\mathrm{b}}$ \\ ${ }^{a}$ Centre for Research and Studies in Sociology, University Institute of Lisbon, Portugal \\ ${ }^{\mathrm{b}}$ Department of Health Sciences, University of Leicester, United Kingdom \\ ${ }^{\text {c }}$ EPIUnit - Institute of Public Health, University of Porto, Portugal \\ d ERCOMER, Utrecht University, Netherlands
}

\section{A R T I C L E I N F O}

\section{Article history:}

Available online 23 April 2015

\section{Keywords:}

Public participation

User involvement

Mental health

Ethnic minorities

Marginalised groups

Participation chain model

Netherlands

\begin{abstract}
A B S T R A C T
Migrants and ethnic minorities are under-represented in spaces created to give citizens voice in healthcare governance. Excluding minority groups from the health participatory sphere may weaken the transformative potential of public participation, (re)producing health inequities. Yet few studies have focused on what enables involvement of marginalised groups in participatory spaces. This paper addresses this issue, using the Participation Chain Model (PCM) as a conceptual framework, and drawing on a case study of user participation in a Dutch mental health advocacy project involving Cape Verdean migrants. Data collection entailed observation, documentary evidence and interviews with Cape Verdeans affected by psychosocial problems $(n=20)$ and institutional stakeholders $(n=30)$. We offer practice, policy and theoretical contributions. Practically, we highlight the importance of a proactive approach providing minorities and other marginalised groups with opportunities and incentives that attract, retain and enable them to build and release capacity through involvement. In policy terms, we suggest that both health authorities and civil society organisations have a role in creating 'hybrid' spaces that promote the substantive inclusion of marginalised groups in healthcare decision-making. Theoretically, we highlight shortcomings of PCM and its conceptualisation of users' resources, suggesting adaptations to improve its conceptual and practical utility.
\end{abstract}

๑) 2015 Elsevier Ltd. All rights reserved.

\section{Introduction}

Public participation in healthcare decision-making is increasingly regarded as fostering more responsive policies, better services and, consequently, healthier populations (Frankish et al., 2002; WHO, 2006). Perhaps because of these promises, it is sometimes assumed that accomplishing inclusive participation is just a question of "getting the mechanisms and methodologies right" (Cornwall, 2008: 279). In practice, however, user participation is challenged by various constraints (Simmons and Birchall, 2005; Renedo and Marston, 2014), affecting some groups more than others. Migrants and ethnic minorities are particularly under-

\footnotetext{
* Corresponding author. University Institute of Lisbon (ISCTE-IUL), Centre for Research and Studies in Sociology, Avenida das Forças Armadas, 1649-026 Lisbon, Portugal.

E-mail address: claudia_defreitas@yahoo.com (C. de Freitas).
}

represented in the spaces created to give citizens voice (Sozomenou et al., 2000). Lack of awareness of opportunities for participation, insufficient mobilisation efforts, lack of resources and mismatches between users' aims and the aims favoured within participatory spaces undermine their involvement (Ibid.; Rutter et al., 2004; De Freitas, 2013). Excluding minority groups from the health participatory sphere may neglect alternative understandings that challenge dominant constructions of health and healthcare (Campbell et al., 2010), weakening participation's capacity to promote transformative change (De Freitas et al., 2014) - that is, participation that is "underpinned by a dialogical orientation" (Aveling and Jovchelovitch, 2014: 36) and which thus has the potential to transform preconceived understandings and result in wider change, rather than reinforcing prior positions and power relationships (cf. Campbell et al., 2010; Aveling and Martin, 2013). Moreover, it may produce or exacerbate health inequities, as policies and services become increasingly adapted to the demands of 
vocal majorities (WHO, 2006; El Enany et al., 2013). This is especially problematic when healthcare systems are dominated by market principles, where preferences of patients are constructed in consumerist, individualised terms, and social-structural constraints on healthcare provision are disregarded (Campbell, 2014). The need to broaden the demographic representativeness of participatory initiatives to include marginalised groups, such as poorer and minority-ethnic groups, has been identified in many OECD healthcare systems (e.g. Martin, 2008a).

So far, few empirical studies have focused on what works to bring marginalised groups into health participatory spaces. This paper seeks to help fill this gap by examining the factors that influence minority service users' decisions to get involved and stay engaged, through study of a successful mental health advocacy project hosted by a Dutch user organisation. We use Simmons and Birchall's (2005) Participation Chain Model as our conceptual starting point. This model attempts to offer a comprehensive understanding of the conditions required to enable and sustain involvement, including (i) 'demand-side' factors (the incentives that encourage users to become involved), (ii) 'supply-side' factors (the resources users need to participate, and efforts to mobilise them), and (iii) the 'institutional dynamics' of involvement itself (the way participatory processes, positively or negatively affecting continued involvement). While the Model seems to offer a clear inventory of the necessary and sufficient conditions for involvement, we highlight shortcomings in its conceptualisation, and suggest modifications with important theoretical and practical consequences for the model's use in informing participatory initiatives that value the contribution of marginal groups.

\section{Background}

Political encouragement for citizen engagement in healthcare has increased considerably in recent decades, "levering open arenas once closed off to citizen voice or public scrutiny" (Cornwall, 2004: 75). These developments are part of a wider shift toward participatory governance originating from concerns with unresponsive services and rising democratic deficits, and demands from increasingly diverse constituencies for inclusion in decisions affecting their lives (Barnes et al., 2004a).

The creation of participatory spaces to which ordinary people are invited has emerged as a key strategy for promoting participatory governance and enhancing democracy (Ibid.). These invited spaces (Cornwall, 2004) are expected to reduce the gap between state and citizens by operating as an interface for dialogue and collaboration in, for example, ensuring fairer distribution of the social determinants of health. However, invited spaces have been criticised in many studies, which highlight how, far from being transformative, they leave existing power relationships unaddressed, resulting in the imposition of established norms of conduct and unexamined preconceptions about service provision (Barnes et al., 2004a; Rose et al., 2010; Campbell et al., 2010). For marginal groups who demur from such hegemonic assumptions, such as migrant and ethnic minority (MEM) groups and mental health service users, the result can be continued marginalisation, with invited spaces acting as spaces for the reassertion of dominant views and the delegitimisation of challenge founded in alternative forms of knowledge (Beresford, 2002; Barnes et al., 2004b), or the 'professionalisation' of portions of the marginal group whose input aligns with dominant views (El Enany et al., 2013). But invited spaces of this kind are not the only form of participatory space. In several countries, grassroots action has given rise to what Cornwall (2004) calls popular spaces. These may be more autonomous and subversive in nature, with potential to equip participants with the skills and confidence necessary to occupy and reshape spaces created 'from above' (Campbell et al., 2010; Aveling and Martin, 2013; Aveling and Jovchelovitch, 2014).

Popular spaces in particular hold tremendous potential to transform prior viewpoints, develop new knowledge, and foster development of provision which is more needs-oriented and accountable to users (Campbell et al., 2010; Vaughan, 2014). Invited spaces, too, despite their roots, can become forums of inclusivity and empowerment, where marginalised views are given greater attention (Cornish, 2006; Renedo and Marston, 2014; Renedo et al., 2015). Nevertheless, within both kinds of space, inequalities in socio-economic status, communication skills and self-confidence may lead some-usually those already marginalised-to silence themselves. These inequalities may also be instrumentalised by more powerful others to bar the entry or impede the influence of disadvantaged citizens in participatory spaces (Aveling and Martin, 2013; Aveling and Jovchelovitch, 2014). Thus unless specific efforts are made to guarantee participatory spaces' inclusiveness for all social groups, participation may actually reinforce inequalities instead of reducing them (Guijt and Shah, 1998). This demands attention to the issues of (i) how to recruit users from marginalised groups, (ii) the resources they need to participate and can offer through participation (e.g. alternative understandings that may be neglected by dominant approaches to healthcare provision), and (iii) how the dynamics of the participatory space itself (whether 'invited', 'popular' or a hybrid) value or suppress these alternative viewpoints. This paper addresses all three sets of issues, answering the central question: how can the contribution of marginalised groups best be encouraged, valued and sustained through participatory initiatives? In so doing, we start from the framework offered by Simmons and Birchall's (2005) Participation Chain Model, which as we explain next helpfully enumerates these issues.

\section{Theoretical framework}

The Participation Chain Model (PCM) (Fig. 1) seeks to provide "a systematic framework for understanding what makes public service users participate" (Ibid.: 260), covering the full range of conditions necessary for participation, including:

- individual and collective benefits that might derive from participation, and which thus motivate people to participate (demand-side factors);

- participants' prior resources, and the mobilisation process that encourages them to participate (supply-side factors);

- the institutional dynamics of participation, i.e. the way the participation process itself, as governed in part by wider institutionalised expectations and priorities, encourages or discourages participation.

Each on its own is a necessary but insufficient condition for

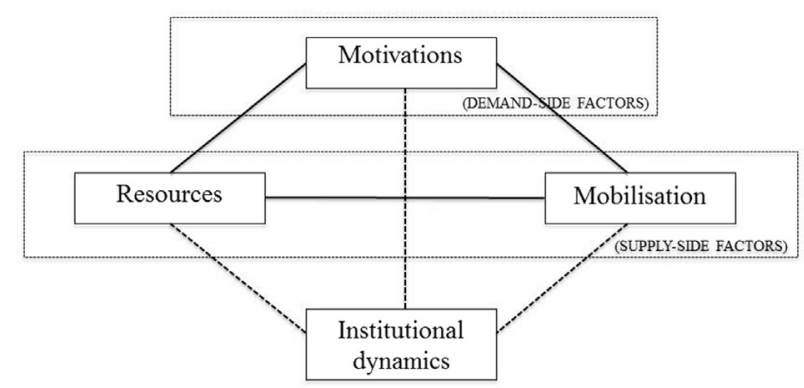

Fig. 1. Participation chain model. Source: Adapted from Figure 9 in Simmons and Birchall (2005: 278). 
participation: motivations, resources, mobilisation and institutional dynamics of involvement are all fundamental links in the participation chain that "need to be joined together, in a coordinated way, if participation is to be effectively strengthened" (Ibid.: 278).

PCM responds in particular to critiques of economistic, rational choice-based approaches that explain participation in terms of an individual's cost-benefit calculus of personal gain, by accounting for the role of more collective incentives (e.g. sense of community, shared values and shared goals) in such decisions. Empirical applications of PCM suggest that collectivist motivations outweigh individualistic ones in participants' decisions to stay engaged (Simmons and Birchall, 2005, 2007), confirming the limitations of viewing participation in individual-rational terms.

In identifying the variables that must be addressed to secure participation, PCM provides a highly practical framework for improving participation levels, which as discussed above can be highly challenging, especially for marginalised groups. Correspondingly, the framework has been cited widely in academic papers, practice-oriented textbooks and policy about participation in health and social care (e.g. SCIE, 2007; Hatton, 2008; De Freitas, 2011; Law et al., 2013), though efforts to validate the Model have been less frequent (Simmons and Birchall, 2007). Perhaps partly in consequence of this, PCM arguably represents a somewhat partial framework. Notably, it offers rather a more detailed exposition of 'demand-side' than 'supply-side' factors. Simmons and Birchall state as their objective the development of a general model that "would incorporate both demand and supply side variables" (2005: 271), but acknowledge that their "main interest has been at the level of incentives" (Ibid.: 278), i.e. demand-side factors such as personal and collective benefits derived for oneself and one's community. By comparison, their theorisation of supply-side factors (efforts to mobilise users, and resources such as time, "skills and confidence"-Ibid.: 271) and of institutional dynamics (the influence of "cultural and institutional factors on attempts to foster and sustain (or sometimes block and frustrate) users' political participation"-Ibid.: 273) is less detailed; these are crucial links in the chain, but not ones that are given extensive analytical treatment, and not ones that have been expanded in the subsequent literature.

In this article we argue that this conceptual imbalance limits the usefulness of PCM as originally formulated for both theoretical and practical purposes. We suggest how the Model might be improved as a tool for ensuring involvement of marginalised groups, particularly in terms of how it conceptualises supply-side 'resources' for involvement and the dynamics of the process.

\section{User participation in Dutch healthcare governance}

Dutch user organisations pioneered public participation in healthcare governance in the 1970s (Haafkens et al., 1986). For about two decades, they were examples of popular spaces, emerging out of mental healthcare users' needs to voice disgruntlement with oppressive practices of care and defend their rights. In the 1990s, the Dutch government recognised user organisations as official partners in healthcare policy-making and began funding them to represent users' views (Nederland et al., 2003). This was part of wider reforms aimed at transforming Dutch healthcare into a quasi-market, with user organisations expected to work as a counterweight to other market agents (service providers and insurers).

This objective was not entirely realised. User organisations are insufficiently equipped to deal with the current demand for participation in decision-making, and lack political clout compared to other agents (Van de Bovenkamp et al., 2010). In addition, Dutch user participation is dominated by the native middle-class segment of citizenry (Nederland et al., 2003). For example, MEM groups are not generally represented in Dutch user organisations or invited spaces (De Graaf and Eitjes, 2004). The delegation of responsibility from government to market agents for the development of diversity-sensitive healthcare services in 2004 (Ministerie van VWS, 2004)-a pattern mirrored in other OECD countries that increasingly rely on market mechanisms for allocating healthcare resources (see for example Beresford, 2002) - makes the question of how to ensure participation from MEMs and other marginalised groups all the more pressing.

\section{Research setting and methods}

Our findings derive from a qualitative case study of minority user participation in a community-based mental health advocacy project - Project Apoio, created by a user organisation in Rotterdam to promote Cape Verdean migrants' rights and access to mental healthcare. We selected this project as a positive exception to the general pattern of poor involvement of minorities in the Dutch health participatory sphere. In 2003 , a survey concluded that $62 \%$ of the 141 user organisations surveyed did not represent MEMs; of those that did, only $5 \%$ were entirely dedicated to advocating for MEMs' interests (De Graaf and Eitjes, 2004). Although Project Apoio was developed in an organisation dominated by native staff, the Dutch Intercultural Centre for Mental Health Expertise classified it as offering good practice in its engagement of a 'hard-to-reach' minority group (Smulders, 2003). Apoio thus represents what Flyvbjerg (2006) calls a deviant case, sampled not for typicality but distinctiveness. Deviant cases facilitate understanding of "deeper causes behind a given problem and its consequences [rather than] describe the symptoms of the problem and how frequently they occur" (Ibid.: 229) and, in the case of positive deviant cases, can start to identify ways of addressing these causes.

Cape Verdean immigrants started settling in the Netherlands in the 1950s. Up to the early 2000s they were largely unknown to mental healthcare providers and had no voice in healthcare decision-making. The stigmatisation of mental illness, communication problems and difficulties in navigating the healthcare system undermined Cape Verdeans' use of and involvement in mental healthcare (Beijers and De Freitas, 2008). Project Apoio sought to tackle these problems. It ceased its activities in 2009 when its host organisation, Basisberaad Rijnmond, filed for insolvency.

Project Apoio created several participatory initiatives including comissão de apoio-a user committee set to disseminate information about the project, enable dialogue between users, providers and health authorities and foster Cape Verdeans' access to psychosocial care-and grupo de conversa-a peer-support group promoting exchange of emotional, informational and social support between people affected by psychosocial distress. These spaces facilitated the engagement of dozens of Cape Verdean users. Employing an approach sensitive to both top-down and bottom-up incentives for participation, Project Apoio's participatory initiatives became an example of what might be termed 'hybrid participatory spaces': spaces sponsored by public authorities which maintain a direct connection with the local user movement.

\subsection{Data collection and analysis}

Case study fieldwork was undertaken over 23 months by CF (January 2005-June 2006; September 2007-January 2008) deploying in-depth semi-structured interviews, participant observation and document collection.

Interviews focused on enablers and inhibitors of participation. They were carried out with two clusters of participants selected 
through purposive and snowball sampling (Miles and Huberman, 1994): 20 Cape Verdean migrants affected by psychosocial problems, including drug abuse, schizophrenia and depression (14 were directly involved and six received individual support and attended public meetings occasionally) (see Table 1); and 30 institutional stakeholders (nine organisation staff, three users involved in invited spaces, three facilitators of invited spaces, 11 healthcare staff, three researchers, one research centre director). All gave informed consent to audio-record the interviews, which lasted 1-3 h. Interviews were transcribed verbatim and translated from Portuguese and Dutch into English. Participant observation entailed taking part in three meetings of comissão de apoio, 11 sessions of grupo de conversa, five public meetings organised by Project Apoio and six group-therapy sessions for Cape Verdeans. Notes were taken in situ, and subsequently supplemented with additional information. Documentary sources including the Project's interim reports and meeting minutes were examined for issues pertaining to participatory activities' design, delivery and attendance.

All data were stored and analysed with the assistance of MAXqda2. Interpretational analysis was carried out employing inductive and deductive approaches. First, data were analysed using open, axial and selective coding and the constant-comparison method (Strauss and Corbin, 1998), facilitating the emergence and identification of core themes (e.g. 'empowering initiatives') through iterative comparison. During selective coding, extant literature was used to load inductive themes with theoretical sensitivity (Ibid.) (e.g. 'resources'). The explanation-building technique (Yin, 1994) was used, following analytic deduction, to facilitate establishment of causal links between factors identified as enablers of minority users' involvement, e.g. 'motivations', 'resources', 'mobilisation' and 'empowering initiatives'. Ethical approval for this type of study is not required in the Netherlands.

Cape Verdean participants are identified with pseudonyms and institutional stakeholders by occupation. The latter include Project Apoio's coordinator and sole employee.

\section{Findings}

We present our findings under three headings, corresponding with the three categories of the PCM. However, our analysis exposes the limitations of understanding these categories in isolation, pointing instead to the way factors can interact-and in particular, how sustained attention to supply-as well as demand-side factors, in a way not anticipated in PCM, was critical to Project Apoio's ability to ensure active participation from a marginalised group.

\subsection{Creating demand-side factors}

Cape Verdeans got involved for various reasons. Some motivations were personal, including the desire to overcome the stigma attached to mental illness, reduce isolation and make use of mental healthcare. Others related to collective concerns such as commitment to social justice.

Increasing social interaction was a key motive for users. Meeting people and sharing ideas, experiences and anxieties were things many users lost when they started showing symptoms of psychosocial distress. In some cases, users recoiled from their social circles due to feelings of helplessness caused by impairment.

Before, I was very closed off. ( . . . ) I couldn't get myself to go out. My head was tired and I forgot a lot. I didn't have the courage to face people. (Isabel)

In other cases, users were forced to reduce social interaction due to stigmatisation and exclusion by others. Florência, for example, commented on people staring and gossipping about her, making her presence in social gatherings uncomfortable. She was resilient and kept on going, but others like Benvinda stopped attending community events to avoid having to endure intrigues and belittling remarks (fieldnotes).

According to participants, "madness" was perceived as dangerous, contagious and irreversible. The fear of being "infected" by an incurable ailment led many to ostracise those deemed to be "mad". This generated a 'culture of silence' about psychosocial suffering among Cape Verdeans in Rotterdam, driving many participants to deny its existence and refuse mental healthcare.

Project Apoio's participatory initiatives were the first opportunity many participants had to talk about mental illness. Its peersupport group allowed them to meet others facing similar problems and find a 'safe route' into mental healthcare.

I didn't know what was wrong with me for a long time. ( . . ) I spent a lot of time not knowing what to do but [then] I got help [from Apoio] and I improved. ( ... ) [Grupo de conversa] gives me the opportunity to contribute to my community and do something useful for those who don't know much yet about mental illness and what they can do to get better. (Simone)

Table 1

Cape Verdean participants' socio-demographic characteristics and involvement (CdA = Comissão de Apoio; GdC = Grupo de Conversa; PM = public meetings).

\begin{tabular}{|c|c|c|c|c|c|}
\hline Name & Age & Gender & Schooling & Social benefits & Participatory activities \\
\hline Joana & 27 & $\mathrm{~F}$ & 12 years & Unemployment benefits & $\mathrm{CdA} ; \mathrm{PM}$ \\
\hline Cátia & 27 & $\mathrm{~F}$ & 12 years & None & $\mathrm{CdA} ; \mathrm{PM}$ \\
\hline Filomena & 54 & $\mathrm{~F}$ & 4 years & Temporary sickness benefits & $\mathrm{CdA} ; \mathrm{PM}$ \\
\hline Aurora & 30 & $\mathrm{~F}$ & 11 years & Unemployment benefits & CdA; PM \\
\hline José & 60 & $\mathrm{M}$ & 6 years & Pension & $\mathrm{CdA} ; \mathrm{PM}$ \\
\hline Isabel & 54 & $\mathrm{~F}$ & 5 years & Permanent sick leave & CdA; GdC; PM \\
\hline Leonor & 42 & $\mathrm{~F}$ & 3 years & Temporary sickness benefits & $\mathrm{CdA} ; \mathrm{GdC} ; \mathrm{PM}$ \\
\hline David & 71 & M & 7 years & Pension & $\mathrm{CdA}$ \\
\hline Palmira & 64 & $\mathrm{~F}$ & Illiterate & Pension & $\mathrm{CdA} ; \mathrm{PM}$ \\
\hline Márcia & 30 & $\mathrm{~F}$ & 13 years & None & $\mathrm{CdA}$ \\
\hline Sara & 51 & $\mathrm{~F}$ & 12 years & Temporary sickness benefits & GdC; PM \\
\hline Simone & 39 & $\mathrm{~F}$ & 13 years & Temporary sickness benefits & GdC; PM \\
\hline Madalena & 32 & $\mathrm{~F}$ & 4 years & Temporary sickness benefits & GdC; PM \\
\hline Armanda & 47 & $\mathrm{~F}$ & 3 years & Unemployment benefits & GdC; PM \\
\hline Lucinda & 50 & $\mathrm{~F}$ & 6 years & None & PM \\
\hline Benvinda & 30 & $\mathrm{~F}$ & 13 years & Unemployment benefits & \\
\hline Lurdes & 65 & $\mathrm{~F}$ & 2 years & Pension & PM \\
\hline Luís & 52 & M & 4 years & Pension & PM \\
\hline Rosa & 39 & $\mathrm{~F}$ & 4 years & Temporary sickness benefits & PM \\
\hline Florência & 61 & $\mathrm{~F}$ & 4 years & Temporary sickness benefits & PM \\
\hline
\end{tabular}


Facilitating other community members' access to mental healthcare became a strong motivation for users to get more actively involved in Apoio's initiatives, turning what was once a disabling lack of information and confidence into an enabling incentive for participation. Thus lack of resources-something Simmons and Birchall (2005) would categorise as a supply-side impediment-can also act as a demand-side motivation.

Increasing the accessibility of mental healthcare is not enough, however, to improve the psychosocial wellbeing of people subjected to socio-economic deprivation and marginalisation. Many other factors impact on their health, including access to education, employment and housing. To address these social determinants of health, Project Apoio's participants collaborated in delivering information sessions about users' rights, legal and institutional support and the instruments available to redress unfair treatment. As a participant explained, being involved in these sessions enhanced her health literacy and gave her the assurance that she could manage her own care.

Because I participated, I think that if I had a problem today, I know I could ask for a longer appointment [with the doctor] to talk about it. I know I can request an interpreter ( ... ). Learning that you can get a tolk [interpreter] has a really positive effect. It enables people to go to places without needing to call a neighbour to translate. Sometimes people get afraid [neighbours] will find out about their problems. If there's a tolk, they can just make an appointment. (Aurora)

Thus users' demand-side motivations to act (i.e. enacting their entitlement to care) impacted on the supply side of the PCM-by endowing them with an increased sense of autonomy and confidence. As we elaborate in the next section, what we find is a generative relationship between demand-side incentives and supply-side resources.

\subsection{Identifying-and invigorating-supply-side factors}

Despite the incentives to become involved, most users lacked the impetus to join participatory spaces: at first glance participation payoffs seemed too low and too distant, while costs appeared too high (e.g. being labelled mentally ill). Face-to-face invitations were key to mobilising users to get involved:

I asked people directly ... people I knew ( ... ) from Cape Verdean associations ... I asked them whether they wanted to participate in Apoio. And then we created comissão. It was a good group of people, about 30 of them. There're many young people. They distributed flyers. They made programmes in the radio. They passed information to others by word of mouth. They actually broke the ice. (Project coordinator)

As Simmons and Birchall (2005) themselves note, direct recruitment is important when seeking to promote participation. Active mobilisation enables marginalised users to recognise their entitlement to participation. Such an investment can gradually lead users to participate of their own accord, and even become active recruiters themselves.

When I see someone who could benefit from the activities of Project Apoio I start making conversation. I tell them about grupo de conversa and what we do there. I tell them we go there to listen to what others have to say and see if we hear something that can help us find a solution to our own problems. (Madalena)
Madalena heard of Project Apoio for the first time on the radio. She contacted the Project's coordinator and offered to help with finding musicians to play during its inauguration event. Yet it was not until the coordinator asked her personally to contribute to the Project's activities that Madalena decided to actively participate. Like Madalena, many other users refrained from participating because they believed they had nothing positive to contribute. Personal invitations served to reassure them of the legitimacy and importance of their contribution.

But it is one thing to step into a participatory space and voice one's concerns and another to actually influence decision-making. Participatory spaces are "spaces of power" (Cornwall, 2004), where criticism and conflict often arise. Criticism that targets participants' frailties, be they limited knowledge or poor communication skills, can be particularly effective in making people abstain from seeking influence. Thus alongside mobilisation, Simmons and Birchall (2005) identify users' resources-cognitive and communication skills, as well as the capacity to listen, to be assertive, to handle conflict, and so on-as fundamental prerequisites for substantive inclusion. However, few of our participants possessed all these competences before becoming engaged, due to their socioeconomic deprivation and the way this barred access to education and other opportunities.

These deficits meant a crucial component of the supply side was missing: the participation chain was broken, and thus according to PCM, the necessary and sufficient conditions for participation were absent. Yet Project Apoio was able to overcome this problem. Acknowledging Cape Verdeans' resource limitations, Apoio started delivering initiatives aimed at raising awareness about the causes of their disadvantage and the mechanisms they could resort to change them. As users went on participating they began to obtain the resources required to adopt an active role in the governance of their affairs. José, for example, found that participation helped him acquire the skill to voice his concerns, even among people he felt unable to talk to initially:

It helped me learn how to relate to people with different attitudes instead of just sticking to people with a low education like myself. I learned how to liaise with knowledgeable people. (José)

Through time, José got involved in organising public meetings, including one that led to the creation of a therapeutic group specifically designed to address Cape Verdeans' unsatisfied needs. José had become sensitised to these needs as a result of his involvement with Project Apoio.

There're a lot of Cape Verdeans with psychological problems living on the streets, instead of getting care. ( ... ) People used to say: "she's crazy" or "he's insolent". But that's not the case. The person is neither crazy nor insolent. The person has a problem. The person is ill and needs help but doesn't know where to find help. (José)

As the father of a young man committed to a psychiatric prison, José was especially conscious of the problems caused by lack of appropriate help. Yet, for a long time, he withheld that information and took no action. He seemed to be struggling with doubt and selfstigma:

I didn't say anything [about my son's problems to the coordinator]. I spoke to other users and asked them whether schizophrenia was caused by the family or came from the person herself. I was doing sort of research. (José) 
By attending Apoio's public meetings and awareness-raising sessions, and later on participating in their organisation, José acquired the information he required. He also improved his communication skills. Acquiring those resources helped him gain the confidence he needed to discuss Cape Verdeans' mental healthcare needs at public meetings.

Isabel and José spoke [at the public meeting] of the many problems caused by Cape Verdeans' lack of access to mental healthcare. ( ... ) One guest-a psychologist-reacted very favourably. (...) She stressed that, although most Cape Verdean migrants live in her service's catchment area, they have very few Cape Verdean users. "Maybe it's due to stigmatisation," she said. ( ... ) Toward the end of the meeting the psychologist offered to try to find a solution together with Apoio. ( ... ) The meetings seem to be offering opportunities for collaboration. (fieldnotes)

The "solution" took the form of a therapeutic group developed to reach out to Cape Verdeans which, as we explore in the next section, resulted from the joint efforts of Apoio's participants and the psychologist mentioned in the fieldnotes above.

Sharing ideas with powerful people and obtaining their support to promote change made participants like José realise the value of their experience and knowledge. This sense of confidence, together with the existence of opportunities to invigorate their capacity to act, was crucial for users to develop a voice.

Coordinator: They used to go to the debates to get a lesson. They heard the lesson and they went home without saying anything back. It was a monologue. Nowadays, people want to talk. They want to give their opinion. ( ... ) It's like the Dutch say: they are empowered. They're emancipated clients now.

Interviewer: What do you think made them become more participative?

Coordinator: I think they started getting more information about what [healthcare] institutions are meant to do and then they began to bring institutions back to the community to get feedback. People started seeing [institutions' representatives] there and they thought: "No. I'm going to take this opportunity to ask what they have to offer us."

The process of empowerment described by Apoio's coordinator above entailed a process whereby users' became aware of the conditions determining their disadvantage, acted to change them, and became more confident in return. In other words, it involved a process by which a resource deficit on the supply side became an incentive on the demand side, in turn building the supply-side resource. Rather than static prerequisites for involvement, resources are malleable qualities that can interact with motivations for participation and develop as a result of it. And as we see next, a further key feature of Project Apoio was an institutional context that reinforced and enhanced this dynamic.

\subsection{Sustaining demand and reinvigorating supply}

Becoming empowered can be a big step for people who have been repeatedly devalued and who may have internalised a powerless 'self. Changing this state of affairs-overcoming feelings of powerlessness and fuelling users' willingness to act-required the development of empowering initiatives focused on further promoting and sustaining users' resources for participation. Project Apoio's participatory spaces sought to do precisely that. One of its first initiatives was a theatre play aimed at raising awareness of stigmatisation associated with, and care available for, psychosis-a problem that had led several Cape Verdeans to seek Apoio's help. Isabel was one of several users starring in the play. When she first got involved, Isabel was depressed, isolated and had few expectations regarding her contribution to Apoio. After some persistence by the Project's coordinator and her fellow actors, she agreed to appear in the play. She represented a psychotic boy's mother and was applauded for her performance.

I liked it [play] but I felt a little bit of embarrassment (laughs). But it went well ... the boy still calls me "mom" when he sees me (laughs). Some people asked if we'd be doing it again. (Isabel)

This experience helped Isabel overcome the feeling that she had little to say and contribute. With time, she became more confident and decided to get involved in organising public meetings to which mental health professionals, local politicians and academics were invited. These participatory spaces were meant to enable dialogue between users and institutional stakeholders: they were "in-between" spaces (Vaughan, 2014) in which people with very different types of knowledge found a common ground for discussion. As we saw above, it was through one of these meetings that Apoio's committee members, including Isabel and José, engaged a psychologist from a local mental health service and sensitised her to the barriers constraining Cape Verdeans' access to mental healthcare. This encounter resulted in a partnership to design a therapeutic group tailored to Cape Verdeans' needs: receiving care in a language they were familiar with and using an approach (grouptherapy instead of individual therapy) and terminology (referring to 'stress' instead of 'mental illness') that they found less intimidating.

Although the creation of this therapeutic group was an example of how change, and citizenship, can be articulated "from below" (Renedo and Marston, 2014), it was a one-off initiative that did not result in structural change. Nevertheless, it evidenced a process of empowerment through which users like Isabel became aware of the causes of their disadvantage and acquired the confidence necessary to influence local service decision-makers into meeting their community's unsatisfied needs.

Negotiating longer-lasting change in mental healthcare provision would perhaps have been more easily achieved by participating in the service's invited space (its client council). However, Dutch invited spaces held little appeal for Cape Verdeans:

One of the problems is that the sort of work done [at client councils] is very bureaucratic. They must read a lot of documents and the language used is really complex. Natives have problems doing it ... for migrants it's even harder. It's not all that attractive to be in a client council. (Invited space facilitator 1)

Whereas invited spaces in the Dutch system focused largely on the administration and delivery of healthcare, Apoio sought to address a broader range of issues, from users' self-efficacy to the range of barriers that undermine their social inclusion (e.g. stigmatisation, discrimination, socio-economic deprivation and limited access to care). Rather than focussing only on what the state required from participation, as hybrid participatory spaces Apoio's initiatives could include the needs of users too, and thus continued to feed the demand side and nourish the supply side of the participation chain. For users like Isabel above, its activities maintained motivation, increased sense of agency, and strengthened commitment to participation, reinforcing the positive interplay between supply- and demand-side factors. 


\section{Discussion}

As our findings show, minority users' engagement in mental health participatory spaces was motivated by concerns with their own wellbeing and that of others experiencing exclusion. But getting into participatory spaces did not immediately equate with voicing needs and demands. Participants required assistance in building the confidence necessary to take action, within an environment where they felt encouraged to speak their minds and overcome their limitations. This suggests that factors such as individual and collective motivations, mobilisation, and empowering dynamics all play a role in facilitating the involvement of users who are marginalised or stigmatised. To this extent, our findings align with PCM (Simmons and Birchall, 2005), which asserts that user participation depends as much on demand-side factors as it does on supply-side factors.

But our findings also suggest adaptations and developments of the PCM. Although Simmons and Birchall emphasise that "each individual link [in the participation chain] needs to be made as strong as possible" (2007: 590), they focus little on how supply-side factors such as resources influence participation. Our analysis highlights the importance of attending to resources, but also shows how these can interact with the demand side. So for example, active work carried out within empowering participatory settings to improve participants' confidence could feed back into their motivation. Not only are all links important, but they may also join in intricate ways, as depicted in our suggested modified Model (Fig. 2). While a strength of Simmons and Birchall's (2005; 2007) quantitative-associational approach is its ability to assess the relative importance of their factors, it cannot reveal such interdependencies, which require qualitative, interpretive analysis.

More fundamentally, our analysis suggests that PCM's view of supply-side factors requires reconceptualization. Simmons and Birchall tend to construct resources as a prerequisite that influences people's ability to get engaged; they also treat "the prior resources and capacities" possessed by potential participants (2005, p.271, emphasis added) as a relatively fixed constant once participation starts. Our analysis shows this is not the case: rather, resources are malleable, and attending to resources is fundamental to generating not just ability but also willingness for participation. We see in the example of José above how, with the right institutional dynamics, a lack of resources (information, confidence, skills) that had previously led users to believe they had nothing to contribute could translate into a powerful drive to act. Resources may thus build through participation and, in consequence, endow participants with increased capacity and resolve for involvement (Renedo et al., 2015). We thus problematise any easy separation of 'demand' and 'supply' side factors: while this may be a helpful conceptual heuristic, caution is needed to ensure that it does not result in a

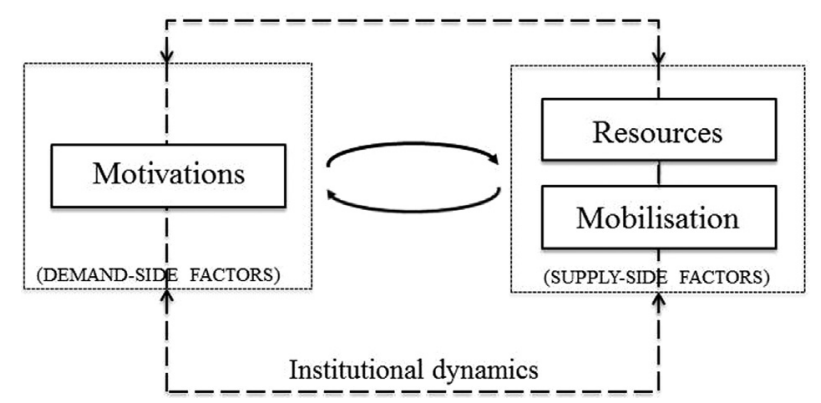

Fig. 2. Modified Participation Chain Model. Demand-and supply-side factors are mutually constitutive, malleable, and develop through Participation. disproportionate focus on improving incentives at the expense of addressing resources. Demand- and supply-side factors interact and constitute one another through the participation process when the right institutional dynamics are in place (Fig. 2).

The implications of this are important academically and practically. Focussing efforts to encourage participation on incentive structures alone risks neglecting material concerns in favour of the psychological. In contexts where multiple sources of discrimination combine to deprive potential participants of resources, this is likely to perpetuate marginalisation. As Roets et al. (2012: 811) argue in the similar Belgian context, the risk of focussing on "the psychological dimension" is that facilitating participation becomes seen as purely "a matter of self-realization": something achieved by providing the right incentive structures, rather than by addressing resources that can be built up. Indeed, this recognition was a crucial part of Project Apoio's unusual success in a context where participation of marginalised groups is usually minimal. As others have commented, then, empowering users must go beyond incentives frameworks. As Vaughan (2014: 190) has it, "while changes at the individual level are an important aspect of empowerment, they are a necessary but not sufficient condition for marginalised people then being able to work together to achieve broader change." Empowerment must extend to invigorating resources and creating nourishing institutional dynamics that enable users to articulate and realise their objectives.

Undoubtedly it was not Simmons and Birchall's intention to suggest that incentives alone are what is needed to achieve participation-but in pursuing the laudable aim of identifying how collective, as well as individual, motivations can give rise to participation, the original formulation of PCM risks overemphasising both, and downplaying the importance of acting upon resources (as well as mobilisation efforts and institutional dynamics) to facilitate participation of marginal groups. Our suggested adjustments to the way the theory conceptualises resources begin, we argue, to rebalance PCM, making it both more useful as an explanatory framework, and more appropriate as a guide for practitioners on the necessary links in the chain, and how to approach them. From a constructivist perspective, it might be argued that even this revised Model is inadequate, since it seeks to label as demand- or supply-side factors constructs that, our empirical analysis suggests, cannot be so easily categorised. However, this also gives the Model its practical value, and so we retain a distinction between the categories put forward by Simmons and Birchall, while trying better to account for the complexity of their interrelationship.

Our findings have further practical and policy implications. Most notably, we add to a growing literature on the characteristics that make participatory spaces more or less empowering and transformative-that is, able to disrupt power imbalances so that encounters are more dialogical and equitable (Aveling and Jovchelovitch, 2014; De Freitas et al., 2014). Project Apoio's status as a hybrid space seemed important here. By offering connections to the state but avoiding being dominated by the professional or bureaucratic concerns which usually characterise invited spaces (Trappenburg, 2008), it encouraged participation of users who might otherwise have been alienated-and allowed participants to engage, as Campbell et al. (2010: 963) have it, "in critical thinking about the social roots of what might previously have been regarded as individual problems." But more than this, it brought representatives of the state and mental healthcare (such as the psychologist who conversed with Isabel and José) into this space, engaging them in these alternative forms of knowledge and creating an 'in-between' space (Vaughan, 2014). In this way, Project Apoio's institutional dynamics did not just permit voice and the articulation of alternative knowledge: it provided a forum for more equitable 
exchange, creating “'receptive social environments' in which the powerful are willing to listen" (Campbell et al., 2010: 964; cf. Vaughan, 2014; Renedo and Marston, 2014). Unlike 'invited spaces' of governance (Cornwall, 2004; Barnes et al., 2004a), it was the representatives of the state who were invited into the spaces of the marginalised, and expected to adapt to their norms. This meant that the potential for influence was perhaps less than might have been achieved via the invited space of the client council, but it did help to generate small, important benefits-such as the development of a group-therapy approach specifically tailored to Cape Verdeans' needs.

Secondly, confirming other studies (e.g. Sozomenou et al., 2000; Simmons and Birchall, 2005), we found that a key step towards empowerment is direct mobilisation. Taking part in participatory spaces entails exposure. Users belonging to communities which stigmatise mentally ill people may avoid participation to avert discrimination. Without a direct invitation by Project Apoio's coordinator, many participants would have stayed inactive. Invitations to participate are experienced as a 'vote of confidence' in their personal competences and ability to make a difference. This, in turn, generates a feeling that one has what it takes to promote change, strengthening users' resources and resolve to stay engaged. Yet in the Netherlands, as in the UK (Martin, 2011), user organisations are becoming less committed to mobilising voiceless groups and equipping them for participation. Many are overloaded with requests to participate in advisory meetings with government, reducing their capacity to reach out to grassroots users (Van de Bovenkamp et al., 2010). Many have also chosen to professionalise to increase their capacity to influence policy, their mobilisation efforts becoming a "search for the right volunteers" who already have the competences required (Ibid.: 81). Recruiting only the most competent users has implications for representativeness and inclusiveness, especially among marginalised groups (Martin, 2008b; El Enany et al., 2013). User organisations must reach beyond these 'participation-ready' volunteers and work actively on the incentives and resources needed by marginal groups, and the institutional dynamics to sustain their involvement. Hybrid spaces and 'in-between' spaces of the kind discussed above may offer one key means of achieving this, and further research on the characteristics of spaces that can achieve empowerment and facilitate transformation through more symmetrical encounters would be beneficial. Indeed, a limitation of this study is that it is does not offer the possibility for a cross-case comparison of participatory spaces engaging different marginalised groups, or healthcare settings.

\section{Conclusion}

This paper shows that participation by marginalised minority users in health decision-making processes can be effectively promoted with the right efforts. It also elucidates the factors determining their involvement. While reaffirming the pertinence of PCM (Simmons and Birchall, 2005), our results highlight the interplay between the demand and supply factors for participation by exposing the complex nature of 'resources'. These insights can cast light on the barriers limiting the inclusiveness of participatory spaces and inform strategies to facilitate a truly plural citizen voice.

Increasing the representation of ethnic minorities and other marginalised groups in healthcare governance requires a proactive approach to participation which acknowledges two things. First, that the incentive structure that attracts minority users to the health participatory sphere is an important but insufficient condition for involvement. Second, that marginalised groups need to build confidence, capacity and a sense of entitlement to practise their citizenship and exploit opportunities for participation. Both health authorities and civil society organisations have a role in creating the hybrid spaces necessary to promote the substantive inclusion of voiceless groups in healthcare decision-making.

\section{Acknowledgments}

This paper derives from a doctoral study funded by the Foundation for Science and Technology (FCT) SFRH/BD/12376/2003. We are grateful to three anonymous reviewers for their insightful and constructive comments.

\section{References}

Aveling, E.L., Martin, G.P., 2013. Realising the transformative potential of healthcare partnerships: insights from divergent literatures and contrasting cases in highand low-income country contexts. Soc. Sci. Med. 92, 74-82.

Aveling, E.L., Jovchelovitch, S., 2014. Partnerships as knowledge encounters: a psychosocial theory of partnerships for health and community development. J. Health Psychol. 19 (1), 34-45.

Barnes, M., Knops, A., Newman, J., Sullivan, H., 2004a. The micro-politics of deliberation: case studies in public participation. Contemp. Polit. 10 (2), 93-110.

Barnes, M., Newman, J., Sullivan, 2004b. Power, participation, and political renewal theoretical perspectives on public participation under New Labour in Britain. Soc. Polit. 11 (2), 267-279.

Beijers, H., De Freitas, C., 2008. Cape Verdeans' pathways to health: local problems, transnational solutions. In: Batalha, L., Carling. J. (Eds.). Transnational Archipelago. Perspectives on Cape Verdean Migration and Diaspora. Amsterdam University Press, Amsterdam, pp. 237-254.

Beresford, P., 2002. Participation and social policy: transformation, liberation or regulation? Soc. Policy Rev. 14, 265-290.

Campbell, C., Cornish, F., Gibbs, A., Scott, K., 2010. Heeding the push from below: how do social movements persuade the rich to listen to the poor? J. Health Psychol. 15 (7), 962-971.

Campbell, C., 2014. Community mobilisation in the 21st century: updating our theory of social change? J. Health Psychol. 19 (1), 46-59.

Cornish, F., 2006. Empowerment to participate: a case study of participation by Indian sex workers in HIV prevention. J. Community Appl. Soc. Psychol. 16 (4), $301-345$.

Cornwall, A., 2004. Spaces for transformation? Reflections on issues of power and difference in participation in development. In: Hickey, S., Mohan, G. (Eds.) Participation: From Tyranny to Transformation? Zed Books, London, pp. 75-91.

Cornwall, A., 2008. Unpacking 'participation': models, meanings and practices Community Dev. J. 43 (3), 269-283.

De Freitas, C., 2011. Participation in Mental Health Care by Ethnic Minority Users. Case Studies from the Netherlands and Brazil. PhD Thesis. Utrecht University.

De Freitas, C., 2013. Aiming for inclusion: a case study of motivations for involvement in mental health-care governance by ethnic minority users. Health Expect. http://dx.doi.org/10.1111/hex.12082.

De Freitas, C., García-Ramirez, M., Aambø, A., Buttigieg, S., 2014. Transforming health policies through migrant user involvement: lessons learnt from three European countries. Psychosoc. Interv. 23 (2), 105-113.

De Graaf, F., Eitjes, H., 2004. Participatie van allochtonen in de gezondheidzorg. Mutant, The Hague.

El Enany, N., Currie, G., Lockett, A., 2013. A paradox in healthcare service development: professionalization of service users. Soc. Sci. Med. 80, 24-30.

Flyvbjerg, B., 2006. Five misunderstandings about case-study research. Qual. Inq. 12, 219-245.

Frankish, C.J., Kwan, B., Ratner, P.A., Higgins, J.W., Larsen, C., 2002. Challenges of citizen participation in regional health authorities. Soc. Sci. Med. 54 (10) $1471-1480$.

Guijt, I., Shah, M., 1998. The Myth of Community. Intermediate Technology Publications, London.

Haafkens, J., Nijhof, G., Van der Poel, E., 1986. Mental health care and the opposition movement in the Netherlands. Soc. Sci. \& Med. 22 (2), 185-192.

Hatton, K., 2008. New Directions in Social Work Practice. Learning Matters Ltd Exeter.

Law, E., Russ, T.C., Connelly, P.J., 2013. What motivates patients and carers to participate in dementia studies? Nurs. Older People 25 (9), 31-36.

Martin, G.P., 2008a. Representativeness, legitimacy and power in public involvement in health-care management. Soc. Sci. Med. 67 (11), 1757-1765.

Martin, G.P., 2008b. "Ordinary people only": knowledge, representativeness, and the publics of public participation in healthcare. Sociol. Health \& Illn. 30 (1), $35-54$

Martin, G.P., 2011. The third sector, user involvement and public-service reform: a case study in the co-governance of health-service provision. Public Adm. 89 (3) 909-932.

Miles, M.B., Huberman, A.M., 1994. Qualitative Data Analysis. Sage Publications, Thousand Oaks.

Ministerie van VWS (Volksgezondheid, Welzijn en Sport), 2004. Brief over allochtonen in de gezondheidszorg (S'-Gravenhagen).

Nederland, T., Duyvendak, J.W., Brugman, M., 2003. Belangenbehartiging door de 
patiënten- en cliëntenbeweging. De theory. Verwey-Jonker Instituut, Utrecht.

Renedo, A., Marston, C., 2014. Creating spaces for effective public involvement in healthcare: an ethnographic study. Sociology. http://dx.doi.org/10.1177/ 0038038514544208.

Renedo, A., Marston, C.A., Spyridonidis, D., Barlow, J., 2015. Patient and public involvement in healthcare quality improvement: how organizations can help patients and professionals to collaborate. Public Manag. Rev. 17 (1), 17-34.

Roets, G., Roose, R., de Bie, M., Claes, L., Van Hove, G., 2012. Pawns or pioneers? the logic of user participation in anti-poverty policy-making in public policy units in Belgium. Soc. Policy \& Adm. 46 (7), 807-822.

Rose, D., Fleischmann, P., Schofield, P., 2010. Perceptions of user involvement: a user-led study. Int. J. Soc. Psychiatry 56 (4), 389-401.

Rutter, D., Manley, C., Weaver, T., Crawford, M.J., Fulop, N., 2004. Patients or partners? Case studies of user involvement in the planning and delivery of adult mental health services in London. Soc. Sci. Med. 58 (10), 1973-1984.

SCIE (Social Care Institute for Excellence), 2007. The Participation of Adult Service Users, Including Older People, in Developing Social Care. SCIE, London.

Simmons, R., Birchall, J., 2005. A joined-up approach to user participation in public services: strengthening the 'participation chain'. Soc. Policy \& Adm. 39 (3) $260-283$.
Simmons, R., Birchall, J., 2007. Tenant participation and social housing in the UK: applying a theoretical model. Hous. Stud. 22 (4), 573-595.

Smulders, R., 2003. Apoio. Een GGZ-consulente Voor Kaapverdianen in Rijnmond. Mikado, Rotterdam.

Sozomenou, A., Mitchell, P., Fitzgerald, M.H., Malak, A., Silove, D., 2000. Mental Health Consumer Participation in a Culturally Diverse Society. Australian Transcultural Mental Health Work, Management Unit, Sydney.

Strauss, A.L., Corbin, J., 1998. Basics of Qualitative Research. Sage, Thousand Oaks.

Trappenburg, M., 2008. Genoeg is genoeg. Over gezondheidzorg en democratie. Amsterdam University Press, Amsterdam.

Van de Bovenkamp, H., Trappenburg, M.J., Grit, K.J., 2010. Patient participation in collective healthcare decision making: the Dutch model. Health Expect. 13 (1), 73-85.

Vaughan, C., 2014. Participatory research with youth: Idealising safe social spaces or building transformative links in difficult environments? J. Health Psychol. 19 (1), 184-192.

WHO, 2006. Ninth Futures Forum on Health Systems Governance and Public Participation. WHO, Copenhagen.

Yin, R.K., 1994. Case Study Research. Sage, Thousand Oaks. 